\title{
Cross-country differences in cyclical variations of male teenage employment
}

\author{
Alfonso Alba-Ramírez ${ }^{*, 1}$ \\ Organization for Economic Cooperation and Development, 2 rue André Pascal, 75775 Paris, France \\ Departamento de Economía, Universidad Carlos III de Madrid, Calle Madrid 126, 28903 Getafe, Spain
}

\begin{abstract}
This article estimates a simple model of employment variation over the business cycle for eight major industrialized countries. It focuses on male teenagers. The main result is that, in six of the eight countries considered, male teenage employment is cyclically more responsive than adult employment.
\end{abstract}

Keywords: Youth labour market; Cyclical variation of employment

JEL classification: $\mathrm{J} 21$

\section{Introduction}

The youth labor market experience over the business cycle hinges on how demand for and supply of youth labor respond to economic fluctuations. To the extent that specific human capital of younger and older workers differ, they are imperfect substitutes for each other. Thus, the demand for the two types of labor will respond differently to the business cycle.

On the one hand, youth labor demand tends to be more responsive to economic fluctuations for several reasons. In economic slumps, low-tenured, younger workers are more likely to be laid off and less likely to be hired because of their relatively higher need for training. Also, lower hiring activity will make it more difficult for new labor market entrants to obtain jobs (Smith et al., 1974). In economic upswings, the demand for youth labor will increase more quickly than that for adults because of the relative wage adjustment. ${ }^{2}$ However, the intensity of the relative wage adjustment can vary across countries.

\footnotetext{
* Correspondence to: Organization for Economic Cooperation and Development, 2 rue André Pascal, 75775 Paris, France.

${ }^{1}$ I am grateful to Pascal Marianna for research assistance.

${ }^{2}$ As industries show different sensitivities to economic fluctuations, youth employment distribution by industries is also likely to be relevant in explaining the youth labor market experience.
} 
On the other hand, the supply of youth labor will be more resilient to labor market conditions than that of adults. One reason for this is that young persons are less likely to have family responsibilities and, therefore, they can more easily leave the labor force or delay their entry into the labor market. Often, difficulties in finding work oblige some young persons to stay in or re-enter school while keeping a tenuous contact with the labor force.

A weak labor market attachment among young workers implies that the unemployment rate can be a misleading indicator of the state of the youth labor market over the business cycle. For this reason, it is more appropriate to analyze the employment-to-population ratio. Moreover, this approach offers the possibility of decomposing employment variations into unemployment and participation.

This article uses time series data to analyze the cyclical component of youth employment. The focus will be on male teenagers in eight major OECD countries: Canada, France, Germany, Italy, Japan, Spain, the United Kingdom and the United States. Data for the period 1972-1992 are obtained from Labor Force Statistics, OECD 1994.

International estimation of aggregate demand effects on youth employment serves to shed light on the nature of youth unemployment across countries. Given each country-specific set of institutions and policies, one would expect different levels of youth employment responsiveness to aggregate demand. This, in turn, conditions a country's success in reducing teenage unemployment. ${ }^{3}$

The paper is organized as follows: Section 2 presents the empirical framework; Section 3 discusses the main results; and finally, Section 4 draws some conclusions and interpretations.

\section{Empirical framework}

The basic empirical framework is similar to the model presented in Wachter and Kim (1982). They consider two categories of labor: older workers who have accumulated specific human capital and younger workers who lack such human capital. The demand for labor depends on output and relative wages. The labor supply for both types of workers is determined by population cohorts and participation rates:

In the long run, we observe variations in youth employment $(Y E)$ that result from cyclical fluctuations in aggregate demand $(A D)$ and changes in the relative supply of young workers $(R S Y)$ :

$$
Y E=F(A D, R S Y)
$$

Of course, there are institutional and policy aspects that may affect the way in which $A D$ and $R S Y$ are linked to $Y E$. For example, the minimum wage ${ }^{4}$ and labor market programs. Paucity

\footnotetext{
${ }^{3}$ As Clark and Summers (1982) point out, "If extensive joblessness occurs only because some young people are essentially unemployable, one would expect changes in aggregate demand to have small effects." However, they showed this not to be the case for the United States.

${ }^{4}$ The minimum wage is relevant because it may prevent adjustments in the youth relative wage. The extent to which this can happen depends on the level of the minimum wage as compared with the average wage in the economy and on its evolution in real terms.
} 
of data prevents us from controlling for these variables. Moreover, given that this paper focuses on cyclical factors in explaining youth employment for major OECD countries, observed differences in estimates will serve to highlight the importance of background institutional and policy dimensions.

For each country, the following reduced-form equation can be estimated:

$$
\ln Y E=\alpha+\beta \ln A D_{t}+\gamma \ln R S Y_{t}+\rho \text { time trend }+u_{t}
$$

where the time trend is intended to pick up structural, social and other trended variables omitted from the equation, and $u_{t}$ is an error term.

Between the two more usual indicators for the youth labor market situation, the youth unemployment rate and the youth employment-to-population ratio, the latter has been chosen. On the other hand, the employment ratio of adult males is taken as a proxy for the aggregate demand, and the relative supply of youth is captured by the ratio of youth to adult population. Thus, the equation to be estimated (subscript for time periods, $t$, omitted) is:

$$
\ln \left(E_{\mathrm{y}} / P_{\mathrm{y}}\right)=\alpha_{0}+\beta_{0} \ln \left(E_{\mathrm{a}} / P_{\mathrm{a}}\right)+\gamma_{0} \ln \left(P_{\mathrm{y}} / P_{\mathrm{a}}\right)+\rho_{0} \text { time trend }+u_{0}
$$

where $E$ is employment and $P$ is working age population. The subscripts ' $y$ ' and 'a' refer to youth and adults, respectively.

As indicated above, one advantage of using the employment-to-population ratio to measure the state of the youth labor market is that it is possible to examine the extent to which cyclical variations in the participation rate make a significant contribution to variations in the employment-to-population ratio. ${ }^{6}$ To do so, consider the following identity:

$$
E / P=L / P(1-U / L)
$$

where $L$ is labor force and $U$ is unemployment. Taking logarithms and differentiating yields

$$
\mathrm{d} \ln (E / P)=\mathrm{d} \ln (L / P)+\mathrm{d} \ln (1-U / L)
$$

Now, let us specify the following two equations, where the explanatory variables are set to be the same as in Eq. (3):

$$
\begin{aligned}
& \ln \left(L_{\mathrm{y}} / P_{\mathrm{y}}\right)=\alpha_{1}+\beta_{1} \ln \left(E_{\mathrm{a}} / P_{\mathrm{a}}\right)+\gamma_{1} \ln \left(P_{\mathrm{y}} / P_{\mathrm{a}}\right)+\rho_{1} \text { time trend }+u_{1} \\
& \ln \left(1-U_{\mathrm{y}} / L_{\mathrm{y}}\right)=\alpha_{2}+\beta_{2} \ln \left(E_{\mathrm{a}} / P_{\mathrm{a}}\right)+\gamma_{2} \ln \left(P_{\mathrm{y}} / P_{\mathrm{a}}\right)+\rho_{2} \text { time trend }+u_{2}
\end{aligned}
$$

Eq. (6) assumes that the labor force participation rate is a function of aggregate demand, relative supply of teenagers and a time trend. Similarly, Eq. (7) can be justified on the same grounds.

\footnotetext{
${ }^{5}$ Other variables like real wages and inflation are excluded because they are highly correlated with the economic cycle (Clark and Summers, 1981).

${ }^{6}$ If youth labor force participation declines in downturns and increases in upturns, the unemployment rate will underestimate the true state of the youth labor market.
} 
If we estimate Eqs. (3), (6) and (7) by the ordinary least squares (OLS) method, identity (4) implies that the following relationships between the coefficients hold:

$$
\alpha_{0}=\alpha_{1}+\alpha_{2}, \quad \beta_{0}=\beta_{1}+\beta_{2}, \quad \gamma_{0}=\gamma_{1}+\gamma_{2}, \quad \rho_{0}=\rho_{1}+\rho_{2} .
$$

This allows us to decompose each explanatory variable effect on employment into the fraction because of changes in participation and the fraction attributable to changes in unemployment.' Identity (8) will no longer be satisfied after correcting for serial autocorrelation. Since doing so does not change the main conclusions of this paper, we report the OLS estimates in order to be consistent with the empirical model. However, such results are qualified according to the estimates corrected for autocorrelation. These have been obtained using a maximum likelihood method and are available upon request.

\section{Results}

In order to examine the cyclical behavior of youth employment according to the model presented above, we focus on male teenagers for they are the most likely to be truly first labor market entrants and their labor force the most affected by economic fluctuations. Teenagers are those persons aged 15/16-19 as opposed to adults who are 25-54 years of age.

\subsection{Employment to population ratio}

Column 1 of Table 1 contains the results of estimating the employment equation as specified in (3). The coefficient for the adult employment ratio is greater than one and significant for all the countries under consideration except Germany and Italy. This means that, except for the latter countries, teenage employment is more responsive to the business cycle than adult employment. The estimated elasticity is particularly high for Japan (8.4) and France (5.2).

Regarding the relationship between the relative supply of male teenagers and their employment, column 1 of Table 1 indicates that an increasing proportion of male teenagers in the population is associated with higher employment ratios in half of the countries (Canada, France, Japan and the United States). In the case of Germany and the United Kingdom, the coefficient obtains a negative sign.

Finally, the coefficient for the time trend is always significant and obtains a positive sign in the case of Canada, the United Kingdom and the United States.

Having obtained some divergent results from estimating the employment equation across countries, the question arises as to what explains the differences in estimates. More important, we are interested in assessing the extent to which such differences are attributable to the behavior of participation in the labor force, or rather, to changes in employment.

\footnotetext{
${ }^{7}$ Note that $\ln (1-r)=r$ only when $r$ is very small. Given that in some countries the youth unemployment rate is quite high, such an approximation is not advisable. If Eq. (7) were estimated with the unemployment rate as the dependent variable, the coefficients will not satisfy the indicated identities.
} 
Table 1

Explanatory factors of employment, labor force participation and unemployment among male teenagers

\begin{tabular}{|c|c|c|c|c|c|c|}
\hline \multirow[t]{2}{*}{ Dep. variable } & \multicolumn{2}{|c|}{$\ln \left(E_{\mathrm{y}} / P_{\mathrm{y}}\right)$} & \multicolumn{2}{|c|}{$\ln \left(L_{\mathrm{y}} / P_{\mathrm{y}}\right)$} & \multicolumn{2}{|c|}{$\ln \left(1-U_{y} / L_{y}\right)$} \\
\hline & Coeff. & $t$ & Coeff. & $t$ & Coeff. & $t$ \\
\hline \multicolumn{7}{|l|}{ Canada } \\
\hline $\ln \left(E_{\mathrm{a}} / P_{\mathrm{a}}\right)$ & 3.683 & 11.94 & 1.829 & 6.48 & 1.854 & 11.46 \\
\hline $\ln \left(P_{\mathrm{y}} / P_{\mathrm{a}}\right)$ & 0.267 & 2.11 & 0.583 & 5.03 & -0.315 & -4.75 \\
\hline Time trend & 0.030 & 6.61 & 0.034 & 8.29 & -0.004 & -1.84 \\
\hline Constant & -0.255 & -1.76 & 0.137 & 1.04 & -0.393 & -5.18 \\
\hline$R$-square & \multicolumn{2}{|c|}{0.91} & \multicolumn{2}{|c|}{0.88} & \multicolumn{2}{|c|}{0.90} \\
\hline DW & \multicolumn{2}{|c|}{1.74} & \multicolumn{2}{|c|}{1.35} & \multicolumn{2}{|c|}{1.00} \\
\hline \multicolumn{7}{|l|}{ France } \\
\hline $\ln \left(E_{\mathrm{a}} / P_{\mathrm{a}}\right)$ & 5.252 & 3.26 & 1.329 & 0.74 & 3.971 & 2.57 \\
\hline $\ln \left(P_{\mathrm{y}} / P_{\mathrm{a}}\right)$ & 1.136 & 4.08 & 1.831 & 5.89 & -0.690 & -2.58 \\
\hline Time trend & -0.026 & -3.38 & -0.030 & -3.47 & 0.004 & 0.55 \\
\hline Constant & 0.845 & 1.87 & 1.841 & 3.66 & -0.987 & -2.28 \\
\hline$R$-square & \multicolumn{2}{|c|}{0.99} & \multicolumn{2}{|c|}{0.98} & \multicolumn{2}{|c|}{0.76} \\
\hline DW & \multicolumn{2}{|c|}{2.35} & \multicolumn{2}{|c|}{1.31} & \multicolumn{2}{|c|}{0.57} \\
\hline \multicolumn{7}{|l|}{ Germany } \\
\hline $\ln \left(E_{\mathrm{a}} / P_{\mathrm{a}}\right)$ & 0.419 & 0.43 & -1.150 & -1.22 & 1.569 & 9.79 \\
\hline $\ln \left(P_{\mathrm{y}} / P_{\mathrm{a}}\right)$ & -0.281 & -4.13 & -0.191 & -2.91 & -0.090 & -8.04 \\
\hline Time trend & -0.022 & -3.88 & -0.026 & -4.87 & 0.004 & 4.90 \\
\hline Constant & -1.010 & -8.43 & -0.913 & -7.92 & -0.097 & -4.95 \\
\hline$R$-square & \multicolumn{2}{|c|}{0.93} & \multicolumn{2}{|c|}{0.92} & \multicolumn{2}{|c|}{0.95} \\
\hline DW & \multicolumn{2}{|c|}{0.56} & \multicolumn{2}{|c|}{0.50} & & \\
\hline Italy & & & & & & \\
\hline $\ln \left(E_{\mathrm{a}} / P_{\mathrm{a}}\right)$ & -1.154 & -0.40 & -6.465 & -2.14 & 5.310 & 2.65 \\
\hline $\ln \left(P_{\mathrm{y}} / P_{\mathrm{a}}\right)$ & 0.787 & 1.18 & 2.211 & 3.18 & -1.424 & -3.08 \\
\hline Time trend & -0.035 & -2.95 & -0.042 & -3.31 & -0.006 & 0.73 \\
\hline Constant & -0.044 & -0.04 & 2.044 & 2.13 & -2.088 & -3.28 \\
\hline$R$-square & & & & & & \\
\hline DW & & & & & & \\
\hline Japan & & & & & & \\
\hline $\ln \left(E_{\mathrm{a}} / P_{\mathrm{a}}\right)$ & 8.432 & 3.48 & 6.751 & 2.80 & 1.680 & 6.87 \\
\hline $\ln \left(P_{\mathrm{y}} / P_{\mathrm{a}}\right)$ & 0.917 & 4.55 & 0.940 & 4.70 & -0.022 & -1.12 \\
\hline Time trend & -0.018 & -6.80 & -0.017 & -6.25 & -0.001 & -5.90 \\
\hline Constant & 0.463 & 1.41 & 0.478 & 1.46 & -0.014 & -0.45 \\
\hline$R$-square & & & & & & \\
\hline DW & & & & & & \\
\hline Spain & & & & & & \\
\hline $\ln \left(E_{\mathrm{a}} / P_{\mathrm{a}}\right)$ & 3.172 & 3.36 & -0.701 & -1.24 & 3.874 & 8.81 \\
\hline $\ln \left(P_{\mathrm{y}} / P_{\mathrm{a}}\right)$ & 0.350 & 0.49 & 1.156 & 2.74 & -0.806 & -2.45 \\
\hline Time trend & -0.027 & -3.39 & -0.039 & -8.24 & 0.012 & 3.31 \\
\hline Constant & 0.282 & 0.24 & 1.502 & 2.16 & -1.219 & -2.26 \\
\hline$R$-square & & & & & & \\
\hline DW & & & & & & \\
\hline
\end{tabular}


Table 1 (Continued)

\begin{tabular}{|c|c|c|c|c|c|c|}
\hline \multirow[t]{2}{*}{ Dep. variable } & \multicolumn{2}{|c|}{$\ln \left(E_{\mathrm{y}} / P_{\mathrm{y}}\right)$} & \multicolumn{2}{|c|}{$\ln \left(L_{\mathrm{y}} / P_{\mathrm{y}}\right)$} & \multicolumn{2}{|c|}{$\ln \left(1-U_{y} / L_{y}\right)$} \\
\hline & Coeff. & $t$ & Coeff. & $t$ & Coeff. & $t$ \\
\hline \multicolumn{7}{|c|}{ United Kingdom } \\
\hline $\ln \left(E_{\mathrm{a}} / P_{\mathrm{a}}\right)$ & 2.917 & 5.18 & 0.719 & 2.50 & 2.200 & 5.36 \\
\hline $\ln \left(P_{\mathrm{y}} / P_{\mathrm{a}}\right)$ & -0.367 & -2.56 & 0.288 & 3.94 & -0.654 & -6.27 \\
\hline Time trend & 0.020 & 4.49 & 0.012 & 5.51 & 0.007 & 2.31 \\
\hline Constant & -1.046 & -3.87 & 0.136 & 0.99 & -1.181 & -6.00 \\
\hline$R$-square & \multicolumn{2}{|c|}{0.79} & \multicolumn{2}{|c|}{0.77} & \multicolumn{2}{|c|}{0.89} \\
\hline DW & \multicolumn{2}{|c|}{1.16} & \multicolumn{2}{|c|}{1.52} & \multicolumn{2}{|c|}{1.10} \\
\hline \multicolumn{7}{|l|}{ United States } \\
\hline $\ln \left(E_{\mathrm{a}} / P_{\mathrm{a}}\right)$ & 3.198 & 14.94 & 1.076 & 7.09 & 2.122 & 14.19 \\
\hline $\ln \left(P_{\mathrm{y}} / P_{\mathrm{a}}\right)$ & 0.393 & 6.15 & 0.429 & 9.48 & -0.036 & -0.82 \\
\hline Time trend & 0.011 & 5.16 & 0.010 & 6.50 & 0.001 & 0.78 \\
\hline Constant & 0.198 & 2.14 & 0.212 & 3.23 & -0.014 & -0.22 \\
\hline$R$-square & \multicolumn{2}{|c|}{0.97} & \multicolumn{2}{|c|}{0.96} & \multicolumn{2}{|c|}{0.94} \\
\hline DW & \multicolumn{2}{|c|}{2.28} & \multicolumn{2}{|c|}{1.92} & \multicolumn{2}{|c|}{2.61} \\
\hline
\end{tabular}

Notes: (a) Equations estimated by ordinary least squares. (b) The time series period is 1972-1992, except for Germany where it is 1972-1990. (c) Teenagers are persons aged 15-19, excepting Spain, the United Kingdom, and the United States where ages 16-19 apply, and Italy where ages 14-19 apply. Adult workers refers to persons aged 25-54 except for Italy where they are 25-59 years old.

\subsection{Participation and unemployment}

The decomposition of employment variations into participation and unemployment shown in identity (5) means that the discrepancy between employment and unemployment can be explained by the different behavior of the labor force participation rate over the business cycle. To probe such behavior, column 2 of Table 1 presents the results of estimating Eq. (6).

The labor force participation rate of teenagers shows a positive and significant elasticity with respect to the adult employment ratio for Canada (1.8), Japan (6.7), the United Kingdom (0.7) and the United States (1.1). The same elasticity is negative and significant for Italy $(-6.5)^{8}$ and in the vicinity of zero for France, Germany and Spain. This result establishes an interesting distinction between the cyclical behavior of the teenagers' participation rate in continental Europe and that of the other four countries.

Among the countries where the participation rate moves parallel to the cycle, the proportion of employment variations explained by changes in labor force participation varies substantially. It is about $80 \%$ in Japan; $50 \%$ in Canada; $34 \%$ in the United States; and $25 \%$ in the United Kingdom.

For all the countries under consideration, estimates from Eq. (7) indicate that the teenage employment rate $(1-U / L=E / L)$ is very responsive to fluctuations of aggregate demand as measured by the adult employment ratio (column 3 of Table 1). The estimated elasticity is particularly high among continental European countries, except Germany. This means that,

\footnotetext{
${ }^{8}$ After correcting for serial autocorrelation, this negative elasticity for Italy becomes insignificant.
} 
reductions (increases) of teenage unemployment in upturns (downturns) tend to be relatively greater in France, Italy and Spain than in other countries. This result is consistent with the finding of more stable participation rates in France, Italy and Spain.

One possible reason for the differences observed in the cyclical variations of teenage participation rates between continental European countries and Canada, Japan, the United Kingdom and the United States may be the different degree to which teenagers combine participation in the labor force and school. By distinguishing between youth enrolled and not enrolled in school, Clark and Summers (1981) found that most of the cyclical response of employment among youth enrolled in school is due to movements in participation rather than unemployment. Indeed, in Canada, Japan, the United Kingdom or the United States, the proportion of teenagers who are both in the labor force and attending school is much greater than in France, Germany, Italy or Spain.

Regarding the lack of responsiveness of teenage employment to the business cycle in Germany and Italy, some observations are worth noting. The case of Germany is unique in that it has the lowest teenage unemployment rate of all OECD countries. The German 'dual system', designed to facilitate the transition from school to work, has proved effective in keeping teenage unemployment very low. This institutional feature may also be one possible explanation for the employment stability among German teenagers. The other country where the employment ratio does not seem to respond to fluctuations in the aggregate demand is Italy. Contrary to German teenagers, Italian teenagers suffer an extremely high unemployment rate. Italy's teenage unemployment is quite responsive to the business cycle despite the fact that participation in the labor force appears stable or slightly anticyclical. ${ }^{10} \mathrm{~A}$ possible reason for this may be the 'additional worker effect': secondary workers (youth) entering the labor market when primary workers (adults) lose their jobs.

\section{Conclusion}

This paper has shown that teenage employment and unemployment are highly sensitive to the business cycle in Canada, France, Japan, Spain, the United Kingdom and the United States. In all of these countries, the respective elasticities are greater than the unity, meaning that both employment and unemployment are more variable among teenagers than among their adult counterparts.

Regarding the labor force participation rate, its responsiveness to the business cycle significantly differs across countries. More particularly, the estimated elasticity was zero or negative in France, Germany, Italy and Spain. This result implies that the beneficial effects of increasing aggregate demand on teenage unemployment become more visible among the

\footnotetext{
"For example, in Canada, the United Kingdom and the United States, around 40\% of school-enrolled male teenagers were also in the labor force as of 1986. This figure for France and Italy was lower than $2 \%$, and for Germany close to $6 \%$ (OECD, 1988).

${ }^{10}$ In the case of Italy, the coefficient for the cyclical variable in the labor force participation and in the employment rate equations becomes insignificant when corrected for serial autocorrelation.
} 
indicated countries. It is also true that these countries tend to experience steeper unemployment increases in the face of a recession.

\section{References}

Clark, Kim B. and Lawrence H. Summers, 1981, Demographic differences in cyclical employment variation, Journal of Human Resources XVI, no, 1, 61-77.

Clark, Kim B. and Lawrence H. Summers, 1982, The dynamics of youth unemployment, in: Richard B. Freeman and David A. Wise, eds., The youth labor market: Its nature, causes and consequences (University of Chicago Press, Chicago).

OECD, 1988, Employment outlook, Paris.

Smith, Ralph E., et al., 1974, Recession and the employment of demographic groups, Brookings Papers on Economic Activity 3, 737-760.

Wachter, Michael L. and Choongsoo, Kim, 1982, Time series changes in youth joblessness, in: Richard B. Freeman and David A. Wise, eds., The youth labor market: Its nature, causes and consequences (University of Chicago Press, Chicago). 